\title{
Validation of a PCR test to predict the presence of flavor volatiles mesifurane and $\gamma$-decalactone in fruits of cultivated strawberry (Fragaria $\times$ ananassa)
}

\author{
Eduardo Cruz-Rus • Rafael Sesmero • \\ José A. Ángel-Pérez • José F. Sánchez-Sevilla • \\ Detlef Ulrich • Iraida Amaya (D)
}

Received: 11 April 2017 / Accepted: 22 September 2017 / Published online: 2 October 2017

(C) The Author(s) 2017. This article is an open access publication

\begin{abstract}
Flavor improvement is currently one of the most important goals for strawberry breeders. At the same time, it is one of the most complex traits to improve, involving the balanced combination of several desired characteristics such as high sweetness, moderate acidity, and the appropriate combination of aroma compounds that are beginning to be delineated in consumer tests. DNA-informed breeding will expedite the selection of complex traits, such as flavor, over traditional phenotypic evaluation, particularly when markers linked to several traits of interests are combined during the breeding
\end{abstract}

Eduardo Cruz-Rus and Rafael Sesmero contributed equally to this work and are listed in alphabetical order.

Electronic supplementary material The online version of this article (https://doi.org/10.1007/s11032-017-0732-7) contains supplementary material, which is available to authorized users.

E. Cruz-Rus · R. Sesmero · J. A. Ángel-Pérez •

J. F. Sánchez-Sevilla $\cdot$ I. Amaya $(\bowtie)$ Instituto Andaluz de Investigación y Formación Agraria y Pesquera (IFAPA) Centro de Churriana, Cortijo de la Cruz, 29140 Málaga, Spain

e-mail: iraida.amaya@juntadeandalucia.es

D. Ulrich

Institute for Ecological Chemistry, Plant Analysis and Stored Product Protection, Julius Kühn-Institute (JKI), Federal Research Centre for Cultivated Plants, Erwin-Baur-Str. 26,

06484 Quedlinburg, Germany

Present Address:

R. Sesmero

Departamento de Biología Vegetal, Universidad de Málaga,

29071 Málaga, Spain process. Natural variation in mesifurane and $\gamma$ decalactone, two key volatile compounds providing sweet Sherry and fresh peach-like notes to strawberry fruits, is controlled by the FaOMT and FaFADl genes, respectively. In this study, we have optimized a simple PCR test for combined analysis of these genes and determined a prediction accuracy above $91 \%$ using a set of 71 diverse strawberry accessions. This high accuracy in predicting the presence of these important volatiles combined with the simplicity of the analytical methodology makes this DNA test an efficient tool for its implementation in current strawberry-breeding programs for the selection of new strawberry cultivars with superior flavor.

Keywords Molecular marker- Genetic screening · Fragaria $\cdot$ Flavor $\cdot$ Aroma $\cdot$ Marker-assisted selection . Breeding

\section{Introduction}

Strawberry is the fruit with the highest production among berries with a global production of over eight million tons (FAOSTAT 2017). The cultivated strawberry (Fragaria $\times$ ananassa) is a relatively new species originated by the accidental hybridization of South American Fragaria chiloensis and North American Fragaria virginiana in a European garden about 250 years ago (Hancock 1999). Systematic breeding of strawberry began shortly afterward and has become an area of substantial economical importance. However, strawberry genetics and breeding is complex due to its 
octoploid genome $(2 n=8 \times=56)$, which is thought to have originated through interspecific hybridization (allopolyploidy) involving up to four species (Rousseau-Gueutin et al. 2009; Tennessen et al. 2014). Recent studies indicate that one of the four subgenomes originates from the diploid donor $F$. vesca, one from the diploid $F$. iinumae, and the remaining two from an unknown ancestor close to $F$. iinumae (Tennessen et al. 2014). These and other studies have shown that the genome of $F$. vesca (Shulaev et al. 2011) can be used as a reference for genomic studies but also that the genome of octoploid Fragaria species has suffered typical genomic changes after polyploidization such as gene loss and genetic rearrangements between the four subgenomes (Rousseau-Gueutin et al. 2008; Sargent et al. 2012; Tennessen et al. 2014; Sánchez-Sevilla et al. 2015). Due to the possibility of up to eight alleles from four homoeologous loci contributing to the variation in each particular gene, improving agronomical and fruit quality traits can be extremely challenging in this species (Lecerteau-Köhler et al. 2012).

Traditionally, strawberries have been highly appreciated for their flavor, which results from a combination of sugars, acids, and volatile organic compounds (VOCs). However, breeding efforts during the last two centuries have been very intensive in industry-demanded targets such as fruit size and shape, yield, pest resistance, fruit firmness, and postharvest life, improvements that have sometimes come at the expense of sensory qualities (Folta and Klee 2016; Ulrich and Olbricht 2016). This tendency is changing; consumer preferences are now taken into account, and the evaluation of total sugar content using soluble solid content (SSC) and acidity in fruits are included at different time points during breeding programs. However, volatile evaluation is expensive, not amenable to high-throughput assays, and as a result, aroma is more difficult to breed for and beyond the scope of the majority of current breeding programs.

Despite the interest in fruit flavor improvement, markers linked to this complex trait are difficult to develop due to the complexity of the different primary and secondary biochemical pathways involved in the biosynthesis of these compounds (Klee 2010). Moreover, volatile patterns in a particular cultivar are also regulated by developmental and environmental cues (Jouquand et al. 2008; Olbricht et al. 2011; Schwieterman et al. 2014). More than 360 VOCs have been identified in strawberry, and the definition of the key chemical constituents of strawberry aroma (character impact compounds) varies among different studies. Three different approaches have been used to estimate character impact compounds, i.e., (1) the relation of quantity and odor thresholds for human perception (aroma value concept), (2) gas chromatographyolfactometry, and (3) quantity and correlation with sensory attributes by consumer test panels (Larsen and Poll 1992; Larsen et al. 1992; Schieberle and Hofmann 1997; Ulrich et al. 1997; Prat et al. 2014; Schwieterman et al. 2014; Ulrich and Olbricht 2016). In general, common VOCs across the different studies contributing to the fruity flavor of strawberry are esters such as methyl and ethyl butanoates, and methyl and ethyl hexanoates. Terpene linalool has been linked to flowery and sweet aroma and two furanones: furaneol (2,5-dimethyl-4-hydroxy-3(2H)-furanone; DMHF) and mesifurane (2,5-dimethyl-4-methoxy-3(2H)-furanone; DMMF), to fruity and caramel aromas. Other key compounds are $\gamma$-decalactone and $\gamma$-dodecalactone, contributing to fresh peachy aroma and which have been associated with increased perception of sweetness in the fruit (Schwieterman et al. 2014; Ulrich and Olbricht 2016). This is particularly important since total sugar content in the fruit has been negatively correlated with yield parameters (Zorrilla-Fontanesi et al. 2011; Whitaker et al. 2012). Therefore, an alternative solution to increase strawberry sweetness perception without affecting yield is breeding for VOCs acting as sweet enhancers such as $\gamma$-decalactone (Schwieterman et al. 2014).

A comprehensive study in the $232 \times 1392$ mapping population identified QTLs controlling 48 different VOCs during different seasons (Zorrilla-Fontanesi et al. 2012). This study highlighted a high stability of about $50 \%$ of the QTLs when grown in the same cultivation system during three consecutive years. Natural variation in the content of two key VOCs, mesifurane and $\gamma$-decalactone, is controlled by major genes, enabling their identification (Zorrilla-Fontanesi et al. 2012). A combination of metabolomics and expression studies in the progeny lines of this mapping population resulted in the identification of $\mathrm{FaOMT}$ as the gene controlling natural variation in mesifurane content in strawberry (Zorrilla-Fontanesi et al. 2012). Sequence analysis of different $\mathrm{FaOMT}$ promoter alleles from progeny lines with contrasting phenotypes identified a 30-bp indel in the proximal region containing three potential cis-regulatory elements (E-box/RRE motif, MYBL motif, and an ABRE/ACGT motif) that were specific to the functional allele (Zorrilla-Fontanesi et al. 
2012). A marker, FaOMT-SI/NO, flanking this polymorphism was developed, and analysis in the parental and the $95 \mathrm{~F} 1$ progeny lines resulted in $100 \%$ cosegregation of mesifurane presence and the amplification of an allele of $248 \mathrm{bp}$. In contrast, the inactive allele, containing the $30 \mathrm{bp}$ deletion, was amplified by FaOMT-SI/NO marker as a band of 217 bp. Since cultivated strawberry is an allo-octoploid, a number of larger FaOMT alleles not related with the phenotype were also amplified, representing most probably homoeologs from the other three subgenomes. The parental lines 232 and 1392 were both heterozygous for the active and the inactive alleles, and these two marker alleles fitted a 1:2:1 segregation in the F1 population. Therefore, this marker could represent a useful tool for the selection of strawberry cultivars with high concentration, or alternatively without mesifurane, in the fruit.

Using the same mapping population and a genome-wide transcriptome analysis by RNA-seq of two bulked pools of progeny lines contrasting in the content of $\gamma$-decalactone, FaFADl was identified as a key gene controlling this important VOC (Sánchez-Sevilla et al. 2014). Simultaneously, another group using complementary approaches in a different segregating population identified the same gene required to synthesize $\gamma$-decalactone, which provides "peachy" notes in strawberry (Chambers et al. 2014). Both studies provided evidences that FaFAD1 was essential, as a number of different lines not able to accumulate $\gamma$-decalactone in their fruits presented either a complete deletion of this gene or a radically different sequence, as several primer pairs were not able to detect the gene by PCR (Chambers et al. 2014; Sánchez-Sevilla et al. 2014).

A DNA test to predict the presence/absence of important VOCs in fruits could improve selection efficiency during breeding programs and facilitate the selection of new tastier cultivars. A simple DNA test that can reliably predict the phenotype across diverse germplasm and parental lines is a useful tool for its routine application in strawberry breeding. In order to reduce the cost and labor of volatile phenotyping, we selected a core collection of cultivars representing the genetic diversity of the species based on analysis of diversity and genetic structure. Here, we report the development of a single diagnostic test for both VOCs mesifurane and $\gamma$-decalactone and validate its predictive capacity in a diverse collection of strawberry cultivars.

\section{Material and methods}

Plant material, DNA isolation, and volatile extraction

Strawberry accessions used in this study were collected at the IFAPA strawberry germplasm collection (ESP138) located at Centro IFAPA de Churriana, Málaga, Spain (Table 1). A total of 71 accessions were selected to represent both a broad view of the cultivated strawberry varieties and a significant representation of the cultivars adapted to Mediterranean/Californian climates, which are commonly used founders in current breeding programs and the most actively commercialized cultivars worldwide (Faedi et al. 2002; López-Aranda et al. 2011). About half of the 71 accessions have been selected based on previous studies of genetic diversity in strawberry (Gil-Ariza et al. 2009; Horvath et al. 2011; Sánchez-Sevilla et al. 2015). Likewise, 61 of the 71 accessions were selected based on their distribution across a wide range of different clusters of a Neighbor-Joining tree with a total of 176 strawberry accessions genotyped using 21,971 SNPs (unpublished results) from the IStraw90 Axiom ${ }^{\circledR}$ array (Bassil and Davis et al. 2015). A Neighbor-Joining clustering of the selected 61 strawberry accessions is shown in Online Resource 1 . Three plants per accession were grown under greenhouse conditions and young leaf samples and ripe fruits were harvested for DNA isolation and volatile extractions, respectively. For fruit volatile extractions, ripe fruits were harvested a number of times during the season to ensure at least 20 ripe fruits from each genotype. Leaf and fruit samples were immediately frozen in liquid nitrogen and stored at $-80^{\circ} \mathrm{C}$ until further analyses.

Total genomic DNA from strawberry accessions was isolated from $130 \mathrm{mg}$ of young unexpanded leaf samples, ground in liquid nitrogen, using a modified CTAB method based on that of Doyle and Doyle (1990). DNA concentration was quantified at $260 \mathrm{~nm}$ using a NanoDrop spectrophotometer (ND-1000 V3.5, NanoDrop Technologies, Inc.), and its quality was checked by two absorbance ratios, 260/230 and 260/ $280 \mathrm{~nm}$, and by $0.7 \%(w / v)$ agarose gel electrophoresis.

Sample for semi-quantitation of VOCs were prepared from ripe strawberry fruits stored at $-80{ }^{\circ} \mathrm{C}$ after harvest. To prepare an enzyme-inhibited strawberry juice, a minimum of $200 \mathrm{~g}$ berries from each genotype was used. One mass part of fruits was homogenized in one volume part of a solution of $18.6 \%(\mathrm{~m} / \mathrm{v}) \mathrm{NaCl}$ using a Waring blender for $2 \mathrm{~min}$. The homogenate was centrifuged $4000 \mathrm{rpm}$ for $20 \mathrm{~min}$ at $4{ }^{\circ} \mathrm{C}$. One hundred milliliter of the supernatant 
Table 1 List of strawberry cultivars and other Fragaria species used, mesifurane (DMMF) and $\gamma$-decalactone $(\gamma$-DEC) content (raw data in peak areas) and FaOMT and FaFADI genotypes.
Non-matching results are in italics. ACCID, accession ID at the IFAPA Germplasm bank; -, no data; yes, indicates the presence of volatile when measured in the cited study using different units.

\begin{tabular}{|c|c|c|c|c|c|c|c|c|}
\hline Name & ACCID & Date & Country & DMMF & FaOMT & $\gamma$-DEC & FaFADI & Reference $^{\mathrm{b}}$ \\
\hline 232 & - & 1996 & Spain & Yes & $248 / 217 \mathrm{bp}$ & 0.00 & No & {$[1]$} \\
\hline 1392 & - & 2002 & Spain & Yes & $248 / 217 \mathrm{bp}$ & Yes & $140 \mathrm{bp}$ & {$[1]$} \\
\hline $93-23$ & - & 2006 & Spain & 0.00 & $217 \mathrm{bp}$ & Yes & $140 \mathrm{bp}$ & {$[1]$} \\
\hline $93-34$ & - & 2006 & Spain & 0.00 & 217 bp & 0.00 & No & {$[1]$} \\
\hline $93-10$ & - & 2006 & Spain & Yes & $248 \mathrm{bp}$ & 0.00 & No & {$[1]$} \\
\hline $93-47$ & - & 2006 & Spain & Yes & $248 \mathrm{bp}$ & Yes & 140 bp & {$[1]$} \\
\hline Aguedilla & 519 & 2003 & Spain & 0.00 & $217 \mathrm{bp}$ & 2.10 & No & {$[2]$} \\
\hline Amiga & 480 & 2006 & Spain & 13.86 & $248 / 217 \mathrm{bp}$ & 0.00 & No & {$[3]$} \\
\hline Aromas & 300 & 2010 & USA & 0.00 & $248 / 217 b p$ & 38.65 & $140 \mathrm{bp}$ & {$[3]$} \\
\hline Proprietary cultivar $1^{\mathrm{a}}$ & 288 & 1998 & USA & 5.69 & $248 / 217 \mathrm{bp}$ & 0.00 & No & {$[3]$} \\
\hline Camarosa & 72 & 1992 & USA & 30.66 & $248 / 217 \mathrm{bp}$ & 0.00 & No & {$[3]$} \\
\hline Camino real & 677 & 2003 & USA & 24.81 & $248 / 217 \mathrm{bp}$ & 70.78 & $140 \mathrm{bp}$ & {$[3]$} \\
\hline Candonga & 715 & 2003 & Spain & 0.00 & $248 / 217 b p$ & 51.70 & 140 bp & {$[3]$} \\
\hline Proprietary cultivar $2^{\mathrm{a}}$ & 292 & 1997 & USA & 144.93 & $248 \mathrm{bp}$ & 0.00 & No & {$[3]$} \\
\hline Chandler & 84 & 1983 & USA & 12.73 & $248 / 217 \mathrm{bp}$ & 189.09 & $140 \mathrm{bp}$ & {$[3]$} \\
\hline Cifrance & 664 & 1996 & France & 30.97 & $248 / 217 \mathrm{bp}$ & 281.51 & 140 bp & {$[3]$} \\
\hline Cijosee (or Cireane) & 301 & 1997 & France & 33.23 & $248 / 217 \mathrm{bp}$ & 89.14 & $140 \mathrm{bp}$ & {$[3]$} \\
\hline Commitment & 701 & 2004 & USA & 7.28 & $248 / 217 \mathrm{bp}$ & 0.00 & No & {$[3]$} \\
\hline Coral & 778 & 1993 & Romania & 41.18 & $248 \mathrm{bp}$ & 183.75 & 140 bp & {$[3]$} \\
\hline Deutsch Evern & 304 & 1902 & Germany & 0.00 & $217 \mathrm{bp}$ & 0.00 & No & {$[3]$} \\
\hline Diamante & 302 & 1995 & USA & 10.58 & $248 / 217 \mathrm{bp}$ & 112.95 & 140 bp & {$[3]$} \\
\hline Douglas & 130 & 1979 & USA & 33.50 & $248 / 217 \mathrm{bp}$ & 0.00 & No & {$[3]$} \\
\hline Proprietary cultivar $3^{a}$ & 956 & 2010 & USA & 140.12 & $248 \mathrm{bp}$ & 0.00 & No & {$[3]$} \\
\hline Proprietary cultivar $4^{\mathrm{a}}$ & 955 & 2010 & USA & 641.34 & $248 \mathrm{bp}$ & 11.40 & No & {$[3]$} \\
\hline Elvira & 126 & 1967 & NDL & 0.00 & $248 b p$ & 0.00 & No & {$[4]$} \\
\hline Endurance & 699 & 2004 & USA & 123.27 & 248 bp & 0.00 & No & {$[3]$} \\
\hline Everest & 315 & 1971 & UK & 30.31 & $248 / 217 \mathrm{bp}$ & 0.00 & No & {$[3]$} \\
\hline Festival & 732 & 2000 & USA & 7.13 & $248 / 217 \mathrm{bp}$ & 0.00 & No & {$[3]$} \\
\hline Fuentepina & 879 & 2009 & Spain & 38.37 & $248 / 217 \mathrm{bp}$ & 310.39 & 140 bp & {$[3]$} \\
\hline Galante & 678 & 2004 & USA & 13.72 & $248 / 217 \mathrm{bp}$ & 0.00 & $140 b p$ & {$[3]$} \\
\hline Galexia & 733 & 2004 & USA & 8.46 & $248 / 217 \mathrm{bp}$ & 26.08 & $140 \mathrm{bp}$ & {$[3]$} \\
\hline Gento & 131 & 1967 & Germany & 19.27 & $248 / 217 b p$ & 13.71 & No & {$[3]$} \\
\hline Gigantella & 308 & - & NDL & 20.30 & $248 / 217 \mathrm{bp}$ & 0.00 & No & {$[3]$} \\
\hline Honor & 700 & 2004 & USA & 101.04 & $248 \mathrm{bp}$ & 0.00 & No & [3] \\
\hline Hood & 832 & 1965 & USA & 0.00 & $217 \mathrm{bp}$ & 0.00 & No & {$[3]$} \\
\hline Jucunda & 843 & 1854 & UK & 172.70 & $248 \mathrm{bp}$ & 0.00 & No & {$[3]$} \\
\hline Proprietary cultivar $5^{\mathrm{a}}$ & 854 & 2005 & USA & 131.08 & $248 \mathrm{bp}$ & 0.00 & No & {$[3]$} \\
\hline Macarena & 777 & 2004 & Spain & 0.00 & $217 \mathrm{bp}$ & 0.00 & No & {$[3]$} \\
\hline Mara des bois & 213 & 1992 & France & 76.72 & 248 bp & 0.00 & No & {$[3]$} \\
\hline Medina & 433 & 2002 & Spain & 18.74 & $248 / 217 \mathrm{bp}$ & 0.00 & No & {$[3]$} \\
\hline Mieze Schindler & 307 & 1933 & Germany & 0.00 & 217 bp & 0.00 & No & {$[5]$} \\
\hline Milsei & 77 & 1990 & Spain & 4.88 & $248 / 217 \mathrm{bp}$ & 78.51 & 140 bp & {$[3]$} \\
\hline Naiad & 697 & 2000 & Italy & 35.08 & $248 / 217 \mathrm{bp}$ & 9.94 & 140 bp & {$[3]$} \\
\hline
\end{tabular}


Table 1 (continued)

\begin{tabular}{|c|c|c|c|c|c|c|c|c|}
\hline Name & ACCID & Date & Country & DMMF & FaOMT & $\gamma$-DEC & FaFADI & Reference $^{\mathrm{b}}$ \\
\hline Oso Grande & 104 & 1987 & USA & 162.60 & $248 / 217 \mathrm{bp}$ & 9.14 & No & {$[3]$} \\
\hline Palomar & 856 & 2007 & USA & 12.61 & $248 / 217 \mathrm{bp}$ & 72.98 & $140 \mathrm{bp}$ & [3] \\
\hline Pandora & 39 & 1988 & UK & 0.00 & $217 \mathrm{bp}$ & Yes & $140 \mathrm{bp}$ & [4] \\
\hline Parker & 110 & 1984 & USA & 82.10 & $248 / 217 \mathrm{bp}$ & 3.14 & No & {$[3]$} \\
\hline Pedrone & 809 & 2004 & Spain & 0.00 & $248 / 217 b p$ & 57.80 & $140 \mathrm{bp}$ & [3] \\
\hline Plarionfre (or Chiflon) & 674 & 1999 & Spain & 38.77 & $248 / 217 \mathrm{bp}$ & 5.59 & No & [3] \\
\hline Premial & 316 & 1989 & Romania & 0.00 & $217 \mathrm{bp}$ & 70.13 & $140 \mathrm{bp}$ & {$[3]$} \\
\hline Reusraths aller Krüester & 844 & 1949 & Germany & 37.00 & $248 \mathrm{bp}$ & 0.00 & No & [3] \\
\hline Roxana & 706 & 2000 & Italy & 18.29 & $248 / 217 \mathrm{bp}$ & 0.00 & No & {$[3]$} \\
\hline Rubygem & 839 & 2004 & Australia & 64.20 & $248 / 217 b p$ & 218.31 & $140 \mathrm{bp}$ & [3] \\
\hline Ruby & 673 & 1998 & USA & 75.77 & $248 / 217 \mathrm{bp}$ & 0.00 & No & {$[3]$} \\
\hline Sabrina & 965 & 2009 & Spain & 52.32 & $248 / 217 \mathrm{bp}$ & 555.89 & $140 \mathrm{bp}$ & [3] \\
\hline Santaclara & 884 & 2009 & Spain & 33.50 & $248 / 217 \mathrm{bp}$ & 699.80 & $140 \mathrm{bp}$ & {$[2]$} \\
\hline Splendor & 862 & 2005 & USA & 11.50 & $248 / 217 \mathrm{bp}$ & 0.00 & No & [3] \\
\hline Tioga & 112 & 1964 & USA & 38.86 & $248 / 217 \mathrm{bp}$ & 2.78 & No & [3] \\
\hline Toyonoka & 245 & 1975 & Japan & 0.00 & $217 \mathrm{bp}$ & 0.00 & No & {$[3]$} \\
\hline Ventana & 676 & 1997 & USA & 0.00 & $217 \mathrm{bp}$ & 29.22 & $140 \mathrm{bp}$ & [3] \\
\hline Ville de Paris & 294 & 1929 & France & 58.30 & $248 / 217 \mathrm{bp}$ & 0.00 & No & {$[3]$} \\
\hline Virtude & 866 & 2005 & USA & 18.67 & $248 / 217 \mathrm{bp}$ & 0.00 & No & [3] \\
\hline Viva Patricia & 953 & 2009 & UK & 132.80 & $248 \mathrm{bp}$ & 339.13 & $140 \mathrm{bp}$ & [3] \\
\hline Winter Dawn & 838 & 2009 & USA & 6.05 & $248 / 217 \mathrm{bp}$ & 0.00 & No & [3] \\
\hline Proprietary cultivar $6^{\mathrm{a}}$ & 290 & 1997 & USA & 90.54 & $248 \mathrm{bp}$ & 12.35 & $140 \mathrm{bp}$ & {$[3]$} \\
\hline CS 9/2 (F. chiloensis $\times$ 'Ventana') & - & 2004 & Spain & 6.35 & $248 / 217 \mathrm{bp}$ & 10.17 & No & [3] \\
\hline CS 13/2 ('Camarosa' $\times$ F. chiloensis) & - & 2005 & Spain & 0.00 & $217 \mathrm{bp}$ & 0.00 & No & {$[3]$} \\
\hline F. virginiana UC-11 (Corvalis PI 551495) & 180 & 1974 & USA & 735.49 & None & 12.24 & $140 \mathrm{bp}$ & [3] \\
\hline F. moschata 'Capron Royale' & 591 & - & France & 348.61 & None & 23.36 & $140 \mathrm{bp}$ & [3] \\
\hline F. vesca Blanca & 596 & - & - & 6.95 & None & 0.00 & $140 \mathrm{bp}$ & [3] \\
\hline F. vesca 'Reine des vallées' & 660 & - & France & 0.00 & None & 28.38 & $140 \mathrm{bp}$ & {$[3]$} \\
\hline
\end{tabular}

${ }^{a}$ Driscoll's proprietary material

${ }^{b}$ Phenotype for volatiles obtained in: [1], Zorrilla-Fontanesi et al. 2012; [2], unpublished study; [3], this study; [4], Larsen et al. 1992; [5], Ulrich et al. 1997

was mixed with $10 \mu \mathrm{L}$ internal standard $(0.1 \%(v / v) 2$,6dimethyl-5-hepten-2-ol dissolved in ethanol). For each sample, three 20-mL-headspace vials containing $3 \mathrm{~g} \mathrm{NaCl}$ each for saturation were filled with $10 \mathrm{~mL}$ of the supernatant, sealed with magnetic crimp caps including septum, and stored at $4{ }^{\circ} \mathrm{C}$.

PCR amplification and gel electrophoresis

Primers used for allele discrimination in genes $\mathrm{FaOMT}$ and FaFAD1 were developed previously (ZorrillaFontanesi et al. 2012; Sánchez-Sevilla et al. 2014). The only difference is that for this work, the forward primer FaOMT-SI/NO-F for gene $\mathrm{FaOMT}$ was extended with two additional nucleotides (Online Resource 2). PCRs for individual gene assays were performed in a final reaction volume of $15 \mu \mathrm{L}$ containing $2 \mu \mathrm{L}(\sim 10 \mathrm{ng})$ of template DNA, $3 \mu \mathrm{L} \times 5$ Taq PCR buffer (GoTaq ${ }^{\circledR}$ buffer, Promega Corp., Madison, WI), $200 \mu \mathrm{m}$ deoxyribonucleotide triphosphates (dNTP), $0.2 \mu \mathrm{m}$ of each forward and reverse primer, and 0.5 U Taq polymerase (GoTaq®, Promega Corp., Madison, WI). As positive control of PCR for the dominant marker qFaFAD1, primers q2-FaM6PI-F (5'-CGAGTTTGAGGTCG ATCGGT-3') and FaM6PI-3UTR (5'-ACAG CTTGTTTGCATCTTCCAA- ${ }^{\prime}$ ) were included in the 
reaction at a concentration of $0.2 \mu \mathrm{m}$ each. This primer pair produced an amplicon of $300 \mathrm{bp}$ in all tested accessions allowing differentiation between negative FaFAD1 amplification and total PCR failure. For combined FaOMT/FaFADI assays, alleles of FaOMT served as positive PCR controls for the dominant FaFAD1 marker, simplifying the assay to a combination of only two primer pairs. PCRs were performed in a final reaction volume of $20 \mu \mathrm{L}$ containing the same amount of template DNA as individual assays, $4 \mu \mathrm{L}$ $\times 5$ Taq PCR buffer, $200 \mu \mathrm{m}$ deoxyribonucleotide triphosphates (dNTP), $0.1 \mu \mathrm{m}$ each of the four primers, and $0.5 \mathrm{U}$ Taq polymerase. PCR conditions followed a touchdown protocol as follows: $95^{\circ} \mathrm{C}$ for 3 min followed by 10 cycles of $95^{\circ} \mathrm{C}$ for $30 \mathrm{~s}, 60^{\circ} \mathrm{C}\left(-0.5^{\circ} \mathrm{C} /\right.$ cycle $)$ for $30 \mathrm{~s}$, and $72{ }^{\circ} \mathrm{C}$ for $45 \mathrm{~s}$, then 25 cycles of $95^{\circ} \mathrm{C}$ for $30 \mathrm{~s}, 55^{\circ} \mathrm{C}$ for $30 \mathrm{~s}$, and $72{ }^{\circ} \mathrm{C}$ for $45 \mathrm{~s}$, followed by a final extension at $72{ }^{\circ} \mathrm{C}$ for $5 \mathrm{~min}$.

Gel electrophoresis of PCR samples was carried out using 2\% agarose gels, containing $6 \mu \mathrm{L} \times 20,000$ RedSafe staining solution (Ecogen, Spain) per $100 \mathrm{~mL}$ gel, in TBE buffer under standard electrophoresis conditions.

\section{Semi-quantitation using HS-SPME-GC-FID}

Volatiles were sampled by HS-SPME using a 100-mm polydimethylsiloxane fiber (Supelco, Bellefonte, PA, USA). Initially, vials were equilibrated at $35^{\circ} \mathrm{C}$ for $10 \mathrm{~min}$ in the shaking operation mode ( $300 \mathrm{rpm})$. Then, the volatiles were extracted by exposing the fiber to the vial headspace for $15 \mathrm{~min}$ at $35{ }^{\circ} \mathrm{C}$ under continuous agitation. Thermal desorption was programmed for $2 \mathrm{~min}$ in the injector (splitless mode) at $250{ }^{\circ} \mathrm{C}$, and followed by additional thermal cleaning for $3 \mathrm{~min}$ at $250{ }^{\circ} \mathrm{C}$ (split ratio $1: 10$ ). Incubation of the vials, extraction, and desorption of the volatiles were performed automatically by a MPS2 autosampler from Gerstel (Mühlheim an der Ruhr, Germany).

Chromatography was carried out using an Agilent Technologies 6890 gas chromatograph (Agilent Technologies Deutschland GmbH, Böblingen, Germany) equipped with a flame ionization detector (FID). Compounds were separated on a polar column HP INNOWax, $0.25 \mathrm{~mm}$ ID $\times 30 \mathrm{~m}$ length $\times 0.5 \mu \mathrm{m}$ film thickness with hydrogen as carrier gas at a constant flow of $1.1 \mathrm{~mL} / \mathrm{min}$. The FID temperature was set at $250{ }^{\circ} \mathrm{C}$. Oven temperature conditions were $40{ }^{\circ} \mathrm{C}$ for $3 \mathrm{~min}$, a ramp from 40 to $200{ }^{\circ} \mathrm{C}$ at $3 \mathrm{~K} / \mathrm{min}$ and $15 \mathrm{~min}$ at $200{ }^{\circ} \mathrm{C}$. Samples were run in triplicate.

For substance identification, parallel runs of selected samples were performed using a similar GC instrument equipped with an Agilent 5973 MSD in the electron impact ionization mode $(70 \mathrm{eV})$ under the same conditions and with helium as carrier gas. Chromatograms and spectra were recorded and processed using the Enhanced ChemStation software (Agilent Technologies). Compounds were identified by comparison of their mass spectrum and retention indices to those in the Wiley and NIST05 library, and also by co-elution and comparison of mass spectrum and retention time to those of pure standards (SIGMA-Aldrich; for all VOCs except bisabolol oxide). Total ion chromatograms were integrated using the Agilent Chemstation to obtain peak areas.

\section{Statistical analysis}

Principal component analysis (PCA) and construction of the box plots were performed with the software STATISTICA 7.1 by Statsoft using raw data (peak areas in counts). For the assembly of the heat map, the software Multi Experiment Viewer 4.8.1 (http://www.tm4. org/) was used with the option of a hierarchical cluster analysis. Test prediction performance for FaOMT$\mathrm{SI} / \mathrm{NO}$ and qFaFAD1 markers was analyzed in relation with the presence/absence of mesifurane and $\gamma$ decalactone, respectively. Estimates of accuracy, positive predictive value (PPV), negative predictive value (NPV), sensitivity (or true positive rate), specificity (or true negative rate), and adjusted diagnostic odds ratio (ADOR) were calculated according to Salinas and Zurn et al. (2017). These metrics were calculated for 67 and 71 accessions for FaOMT-SI/NO and qFaFAD1 markers, respectively, and are used as quantitative indicators of the test's ability for accurate diagnosis (Aliu and Chung 2012; Glas et al. 2003). The indicators PPV, NPV, sensitivity, and specificity represent only part of the discriminatory evidence, as high sensitivity may be accompanied by low specificity. In contrast, the ADOR statistic combines the strengths of sensitivity and specificity with the advantage of accuracy as a single indicator (Glas et al., 2003). ADOR accounts for the strength of the association between test result and phenotype and is defined as $[(A D J$ sensitivity $\times A D J$ specificity)/(1 - ADJ sensitivity $) \times(1-A D J$ specificity $))]$, where adjusted sensitivity and specificity values 
resulted from adding 0.5 to every cell of the contingency table (Salinas and Zurn et al. 2017; Glas et al., 2003). ADOR values range from 0 to infinity, with higher values indicating better discriminatory test performance.

FaOMT promoter isolation and analysis

For characterization of the $\mathrm{FaOMT}$ promoter fragment from selected strawberry accessions, PCR and separation in agarose electrophoresis were performed as previously described for FaOMT-SI/NO marker test. Selected bands of about $500 \mathrm{bp}$ from $F$. virginiana UC-11 and F. moschata 'Capron Royale', and 248 bp from $F$. × ananassa cv. 'Aromas', 'Candonga', 'Elvira', and 'Pedrone' were isolated and purified from the agarose gel using the FavorPrep GEL/PCR purification kit (Favorgen Biotech Corp.) and cloned into the pGEMT Easy vector (Promega). Five independent clones were sequenced for each of the three accessions and assembled into individual contigs using the SeqMan tool (DNAStar). Sequence analyses and comparisons were carried out using the Lasergen software (DNAStar) and the tool Clustal W2 from EBI-EMBL.

\section{Results}

A total of 71 strawberry accessions including $65 F$. $\times$ ananassa cultivars, $2 F$. vesca samples, $1 F$. moschata, 1 $F$. virginiana, and 2 hybrids between $F$. $\times$ ananassa and F. chiloensis were used for marker validation (Table 1). Among the collection of 71 selected accessions, the 65 strawberry cultivars included samples from different breeding programs worldwide, including cultivars adapted to cultivation in the United States of America (USA), Germany, France, Spain, Japan, and Australia. This comprehensive panel included historically important cultivars and progenitors from different origins and also cultivars whose fruits have been described as highly aromatic, such as 'Mara des bois' and 'Mieze Schindler' (Ulrich and Olbricht 2016). The accessions from the related Fragaria species were selected based on the high aroma of their fruits, similar to the two hybrids with $F$. chiloensis (CS9/2 and CS13/2), which have been used as initial breeding lines within the IFAPA program. The wide diversity of this set of accessions is illustrated as a Neighbor-Joining clustering in Online Resource 1 using 61 out of the 71 accessions (see "Material and methods"). In this analysis, the selected 61 strawberry accessions were distributed into six clusters with different levels of admixture to the ancestry groups of the complete set of 176 accessions (Online Resource 1).

Phenotypic variation in fruit volatile organic compounds

Fruit volatiles from the strawberry panel were semiquantified using headspace solid phase microextration (HS-SPME) sampling coupled to gas chromatographymass spectrometry (GC-MS), although the data from the $232 \times 1392$ segregating population, 'Elvira', 'Pandora', and 'Mieze Schindler', were previously obtained and reported and data from 'Aguedilla' and 'Santaclara' was obtained from a different ongoing study (Table 1). The quantitative range of the VOC variation in the strawberry collection was remarkable. In Online Resource 3, the range of metabolite variation is depicted as box plots. Out of the 31 VOCs, 25 (80.6\%), including mesifurane and $\gamma$-decalactone, show qualitative effects of substance contents, that is in one or more accessions zero values for the distinct compound were found (Online Resource 4). The most abundant compound was ethyl hexanoate. Regarding mesifurane and $\gamma$-decalactone, 47 accessions $(78.3 \%)$ and 30 accessions $(50 \%)$, respectively, contained these compounds while it was not significantly produced in the remaining samples (below the detection threshold of 6.0). Metabolite variation is visualized by a heat map and a PCA in Fig. 1. In the heat map (Fig. 1a), accessions as well as VOCs are clustered using a hierarchical cluster analysis. As shown in other reports, the accessions from $F$. vesca, F. moschata, and $F$. virginiana were characterized for a different set of VOCs compared to cultivars of $F . \times$ ananassa (Ulrich et al. 2007; Ulrich and Olbricht 2013; Ulrich and Olbricht 2014; Negri et al. 2015). For example, the content of ketones and octanol was higher while the content of nerolidol and $\gamma$-dodecalactone was lower in these wild species compared to $F$. $\times$ ananassa cultivars. The ester methyl anthranilate, responsible for the intense sweet and flowery notes of wild strawberries, was only detected in low levels of 5.51 and 5.01 (relative concentration units in peak area) in two $F . \times$ ananassa accessions: 'Mara des bois' and the hybrid with $F$. chiloensis CS9/2, while showing high accumulation in wild species, ranging from 47.72 in $F$. virginiana to 412 in $F$. moschata (Fig. 1a; Online Resource 4; Ulrich et al. 2007; Ulrich and Olbricht 2013; Negri et al. 2015). Thus, the hierarchical cluster analysis classified the 60 
a

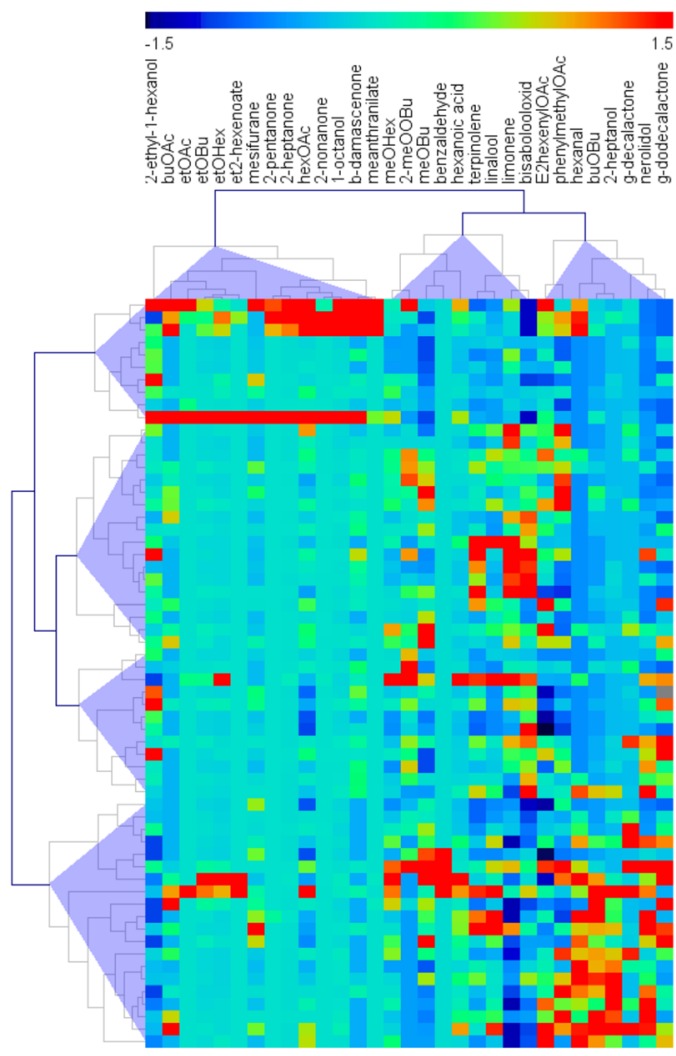

Fig. 1 a Heat map grouped by a hierarchical cluster analysis (HCL) of the VOC composition of 60 samples and derived hierarchy of both cultivar and metabolite relatedness is displayed b
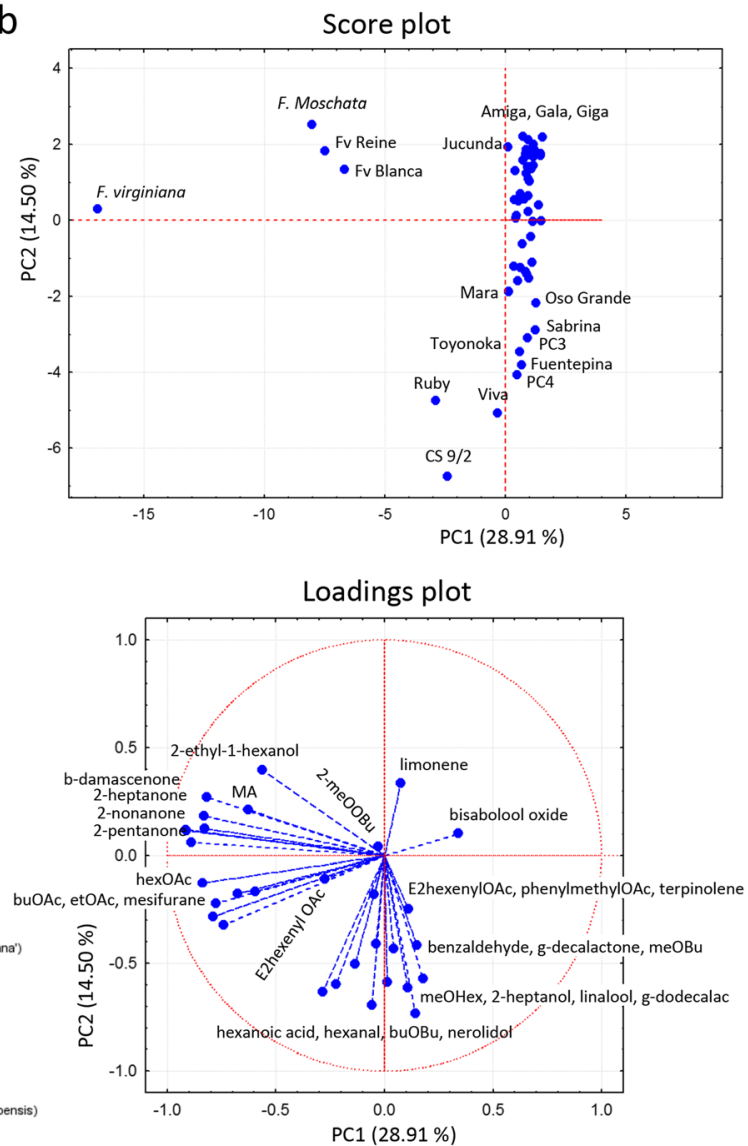

vertically and horizontally, respectively. b Score plot and loading plot of a principal component analysis (PCA) assayed accessions into four clusters, with the four accessions of the three wild species integrated in the top cluster, whereas the two F. chiloensis hybrids grouped in the bottom cluster. As a result of these differences in volatile composition, PCA distributed the majority of cultivars in a stretched cluster while wild species and one of the two hybrids were clearly separated (Fig. 1b).

When using available data for the complete set of 71 accessions, approximately three quarters $(76 \%)$ of the 71 accessions (54) contained mesifurane in their fruits while 17 samples $(24 \%)$ did not produce detectable amounts of this volatile. Regarding $\gamma$-decalactone, 32 accessions $(45 \%)$ presented the volatile in different quantities while it was not significantly produced (below the detection threshold of 6.0) in 39 (55\%) strawberry accessions (Table 1).

\section{Genotyping using FaOMT-SI/NO and qFaFAD1} markers

For genotyping, the 71 strawberry accessions were first PCR tested for amplification of the FaOMT-SI/NO and qFaFAD1 specific markers independently (Fig. 2). The FaOMT-SI/NO marker allows the discrimination of active and inactive alleles of the FaOMT gene based on their amplification size, 248 and $217 \mathrm{bp}$, respectively (ZorrillaFontanesi et al. 2012). However, this marker did not amplify the predictive $217 / 248$ bp bands in the four samples representing the three wild species (Fig. 2b). Instead, larger bands corresponding to other alleles also present in the $F . \times$ ananassa accessions were amplified in these species, as previously reported for the $232 \times 1392$ population (Zorrilla-Fontanesi et al. 2012). Among the remaining 67 samples, including the two hybrids between $F$. $\times$ 
ananassa and F. chiloensis, 15 (22.4\%) were homozygous for the active 248 bp allele, 40 (59.7\%) were heterozygous (presenting both 248 and 217 bp bands), and 12 (17.9\%) were homozygous for the inactive (217 bp) allele (Table 1). In heterozygous samples, the inactive $217 \mathrm{bp}$ allele is amplified less efficiently than the $248 \mathrm{bp}$ allele, resulting in an extremely faint band of $217 \mathrm{bp}$ and difficult discrimination between $248 / 248$ and 248/217 genotypes. However, heterozygous samples present an additional and also faint heteroduplex band that migrates above the 248 bp allele, which allows an efficient determination of the allelic composition of these lines (Fig. 2a).

The qFaFAD1 marker was designed to amplify a 140bp fragment within the second exon of the FaFAD1 gene. Previous analyses in lines of the $232 \times 1392$ population, cultivars such as 'Camarosa' or 'Chandler' resulted in the absence of product upon PCR amplification in those lines lacking $\gamma$-decalactone in their fruits (Sánchez-Sevilla et al.
2014). Therefore, qFaFAD1 is a dominant marker able to identify lines positive for the presence of the $F a F A D 1$ gene but does not allow discrimination between dominant homozygous and heterozygous lines. In order to test the capacity of this marker to predict the presence of $\gamma$ decalactone in strawberry fruits, we PCR tested for specific amplification of FaFAD1 in the diverse set of 71 strawberry accessions (Fig. 2c). Among them, 30 samples (42.3\%) contained the FaFAD1 allele while the remaining 41 samples $(57.7 \%)$ were negative in the PCR analysis.

Evaluation of FaOMT-SI/NO and qFaFAD1 as diagnostic markers for mesifurane and $\gamma$-decalactone content in strawberry fruits

Next, we optimized a FaOMT-SI/NO-qFaFAD1 combined test in which three informative alleles can be present: 248 and 217 bp for FaOMT and 140 bp for FaFAD1. In this
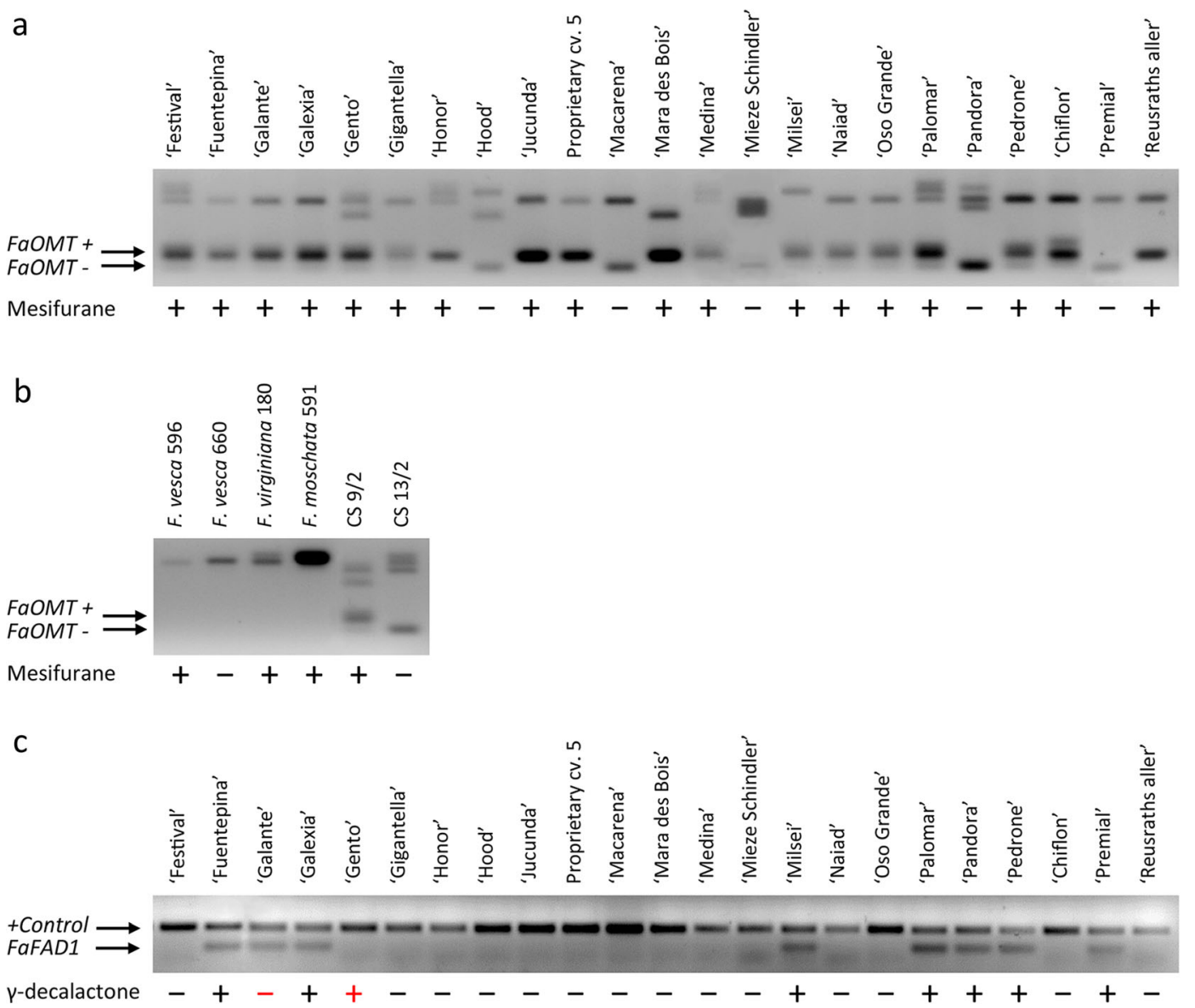

Fig. 2 Examples of PCR bands amplified using FaOMT-SI/NO (a, b) and qFaFAD1 (c) markers in representative samples separated in 2\% agarose gels. Symbols + and - indicates presence and absence of mesifurane or g-decalactone in their fruits, respectively 
multiplexed PCR, the FaOMT-SI/NO products allowed the discrimination between the absence of the FaFAD1 allele in a sample and total PCR failure.

The 71 strawberry accessions were then screened with the combined PCR test, and observed genotypes for $F a O M T$ and FaFADI were identical to those generated using single tests for all accessions (Fig. 3). In this combined test, accession homozygous for the $248 \mathrm{bp}$ allele and heterozygous 248/217 were difficult to differentiate. However, for evaluation of test performance, the presence and absence of the $248 \mathrm{bp}$ allele has been used as diagnostic of the presence of the functional $\mathrm{FaOMT}$ gene. Contingency tables were constructed for both markers using the presence/absence of diagnostic bands
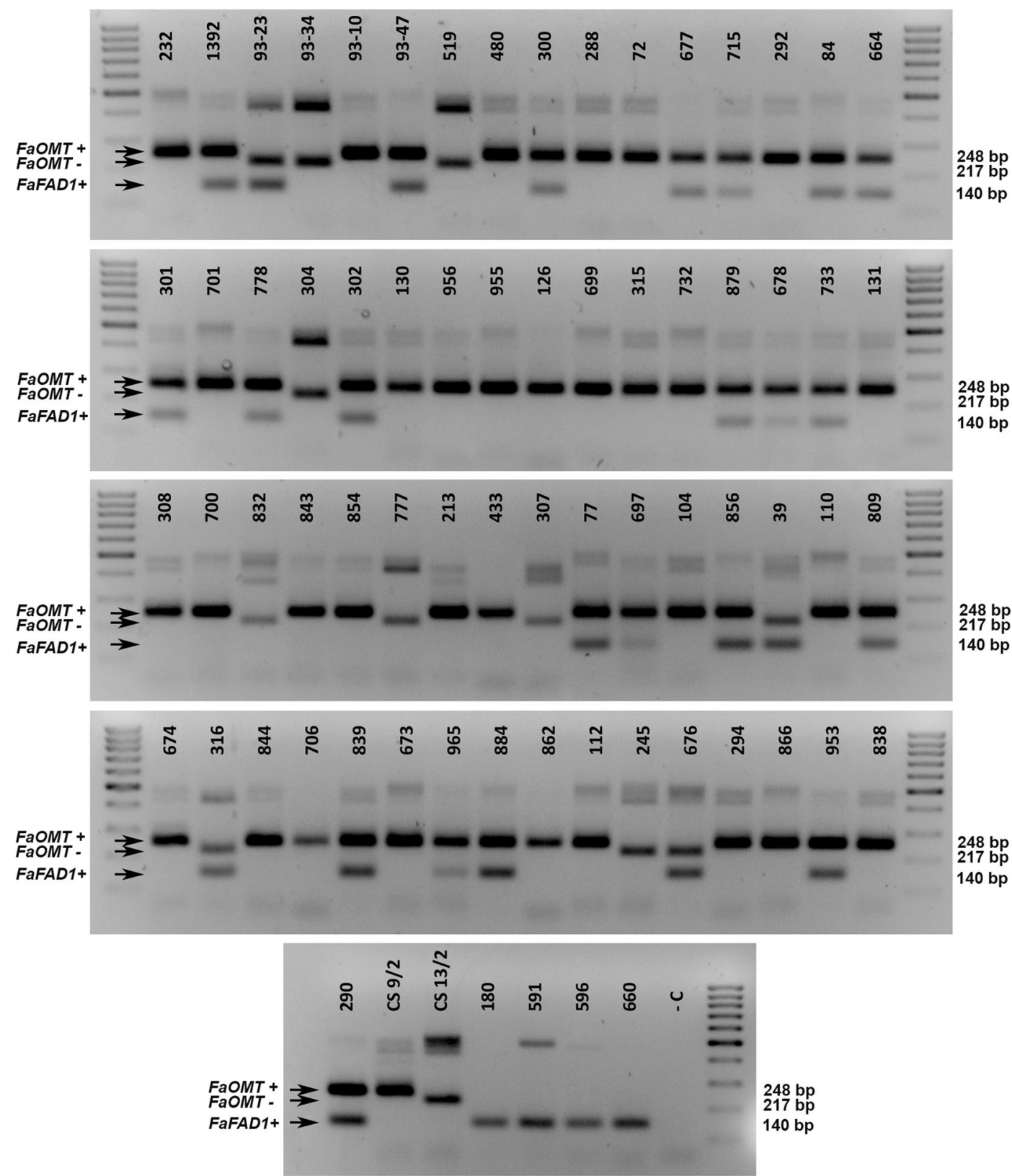

Fig. 3 Combined PCR test using FaOMT and FaFADl markers for prediction of mesifurane and g-decalactone content in strawberry. Accession numbers of the 71 samples correspond to those described in Table 1. Lane M indicates 100-bp DNA ladder. Lane - C, non-template control 
summarized in Table 1, and indicators for test performance were calculated (Table 2). The accuracy and ADOR values for the FaOMT-SI/NO marker were $94.03 \%$ and 286.1 , respectively, indicating a high predictive value for this test. This marker presented maximum values for sensitivity (true positive rate) and NPV, since no false negatives were found (Table 2). Four false positive cases were found corresponding to cultivars 'Aromas', 'Candonga', 'Elvira', and 'Pedrone' and resulted in PPV and specificity values of 0.93 and 0.75 , respectively (Table 2 ). These cultivars presented the functional $248 \mathrm{bp}$ allele in either homozygosis or heterozygosis, but none of them contained mesifurane in their fruits. As previously stated, the FaOMT-SI/NO marker cannot be used for the other Fragaria species, as predictive bands are not amplified. Among those four wild accessions, three contained mesifurane in their fruits while $F$. vesca 'Reine des vallées' did not contain detectable amounts (Fig. 3, Table 1).

The $\gamma$-decalactone 140 bp FaFAD1 allele was diagnostic for 65 out of 71 Fragaria accessions (Table 1) resulting in a predictive power or accuracy of $91.55 \%$. For this marker, the resulting ADOR value was 129.5 (Table 2). Cultivars 'Aguedilla', 'Parker', 'Plarionfre', and 'Tioga' tested negative for the $140 \mathrm{bp}$ allele, and their content of $\gamma$-decalactone was below the detection threshold of 6.0. Therefore, we decided to consider these four accessions as non-producers. Among the six accessions with inconsistencies, 'Galante' and F. vesca 596, presented the $140 \mathrm{bp}$ allele but did not contain $\gamma$ decalactone in their fruits ( 0.93 for PPV) while the four remaining accessions (proprietary cultivar 4, 'Gento', 'Oso Grande', and CS9/2) were negative in the qFaFAD1 test but presented a low, although above threshold content, of $\gamma$-decalactone ( 0.90 for NPV) (Table 2). Other previously described primer pairs spanning the open reading frame of FaFAD1 (SánchezSevilla et al. 2014) also tested negative in these four accessions, suggesting a deletion of this gene or a radically different sequence in these samples, as previously reported for strawberry accessions without $\gamma$ decalactone (Chambers et al. 2014; Sánchez-Sevilla et al. 2014).

Sequence analysis of $\mathrm{FaOMT}$ promoter fragment in samples with contradictory results

In order to investigate the inconsistencies observed between the FaOMT-SI/NO marker and mesifurane production, we isolated and analyzed the sequence of the promoter fragment of $\mathrm{FaOMT}$ amplified by the marker in six accessions including the four false positive samples and two different species: F. virginiana UC-11 and $F$. moschata 'Capron Royal'. For $F$. $\times$ ananassa cultivars 'Aromas', 'Candonga', 'Elvira', and 'Pedrone', the marker predicted the production of mesifurane (presence of the 248 bp allele) but the fruit did not accumulate detectable amounts. In the accessions $F$. virginiana UC-11 and F. moschata 'Capron Royal' that lacked the predictive bands and produced mesifurane, the FaOMTSI/NO marker produced a unique band of about $500 \mathrm{bp}$. For these two accessions, we aimed to determine whether cis-acting elements associated with the $30 \mathrm{bp}$ indel in the $248 / 217$ bp alleles were present in this 500 bp allele that could explain mesifurane production in these two Fragaria species (Zorrilla-Fontanesi et al. 2012).

Sequences of promoter fragments were compared with the functional and inactive alleles previously published from lines 93-62 and 93-23, respectively (Zorrilla-Fontanesi et al. 2012). As shown in Online Resource 5, high homology in described cis-acting elements was observed in the six sequenced alleles when compared to previously characterized alleles. The promoter sequence from 'Aromas', 'Candonga', 'Elvira', and 'Pedrone' was identical to the active 248 bp allele previously characterized from line 93-62 (Online Resource 5). Three specific motifs in this allele have been associated with high $\mathrm{FaOMT}$ expression and production of mesifurane in fruit (Zorrilla-Fontanesi et al. 2012). The promoter sequences from $F$. virginiana and $F$.

Table 2 Indicators of diagnostic performance for FaOMT-SI/NO and qFaFAD1 marker tests

\begin{tabular}{|c|c|c|c|c|c|c|}
\hline Marker test & Accuracy $(\%)$ & Sensitivity & Specificity & PPV & NPV & ADOR \\
\hline FaOMT-SI/NO & 94.03 & 1.00 & 0.75 & 0.93 & 1.00 & 286.1 \\
\hline qFaFAD1 & 91.55 & 0.88 & 0.95 & 0.93 & 0.90 & 129.5 \\
\hline
\end{tabular}

ADOR ranges from 0 to $\infty$ (the higher the number, the better the diagnostic test)

$P P V$ positive predictive value, $N P V$ negative predictive value, $A D O R$ adjusted diagnostic odds ratio 
moschata species, whose fruits contain high levels of mesifurane, were more similar in size and sequence to the promoter of $F v O M T$ from the $F$. vesca reference genome (Shulaev et al. 2011). A 3-bp deletion was observed in these three species in the region where the $30 \mathrm{bp}$ indel is present in $F$. $\times$ ananassa. None of the three motifs associated with mesifurane production were entirely conserved in these two accessions compared with the active $248 \mathrm{bp}$ allele, as previously shown for the $F$. vesca promoter sequence (Online Resource 5; Zorrilla-Fontanesi et al. 2012).

\section{Discussion}

Modern strawberry cultivars are considerably less aromatic than wild species or than the majority of traditional $F$. $\times$ ananassa varieties (Ulrich et al. 2007; Ulrich and Olbricht 2013). Breeding efforts for the selection of new fruit cultivars during the last two centuries have been dedicated to improve traits that are key for growers such as yield, fruit size, and firmness, and this has indirectly resulted in a deterioration of volatile diversity (Folta and Klee 2016). The majority of breeding programs worldwide are now including the evaluation of sugar content and sugar/acid ratio in their selection process. However, volatile quantification is expensive and time-consuming, and therefore beyond the resources of most breeding programs.

Because volatile patterns are developmentally regulated and strongly dependent on environmental cues (Klee 2010), volatile phenotyping represents a bottleneck for improvement of strawberry fruit flavor and aroma. The development of efficient molecular markers for accurate prediction of desired aroma compounds would greatly accelerate the selection of new cultivars with improved characteristics. In this study, we have optimized a single PCR test for evaluation of functional alleles in two genes, FaOMT and FaFAD1, which control the production of mesifurane and $\gamma$-decalactone, volatiles that contribute to sweet Sherry and fresh peach-like notes to strawberry fruits, respectively (Zorrilla-Fontanesi et al. 2012; Chambers et al. 2014; Sánchez-Sevilla et al. 2014). Next, we evaluated the prediction accuracy of these markers by comparing the presence of functional alleles with the occurrence of the volatiles in fruits using a set of 71 diverse strawberry accessions. Marker FaOMT-SI/NO amplified one to five bands of different length in the selected accessions, in accordance with their polyploid nature. In strawberry cultivars, the production of mesifurane has been associated with the presence of an allele of $248 \mathrm{bp}$, while a $217 \mathrm{bp}$ allele, due to a 30-bp deletion in the proximal region of the $\mathrm{FaOMT}$ promoter, causes an inactive allele (Zorrilla-Fontanesi et al. 2012). In this study, approximately $25 \%$ of the accessions did not accumulate significant amounts of mesifurane in their fruits, and frequencies of the 248 and $217 \mathrm{bp} \mathrm{FaOMT}$ allele were approximately 0.5 .

As previously reported for other $F$. vesca accessions, one product of about $500 \mathrm{bp}$ was present in the two accessions of the diploid $F$. vesca tested in this study (Zorrilla-Fontanesi et al. 2012). One or two bands of similar size to that of $F$. vesca FvOMT were detected in the hexaploid $F$. moschata and the octoploid $F$. virginiana. Sequence analysis of the 500 bp promoter fragments of $F$. moschata and $F$. virginiana has confirmed that the $30 \mathrm{bp}$ deletion is not present in these species, as expected for fruits containing mesifurane. However, the three cis-acting elements specific to the $248 \mathrm{bp}$ allele and associated with mesifurane production in the $232 \times 1392$ population were not entirely conserved in these two species. Therefore, currently, we lack an explanation for the high content of mesifurane in fruits of these two species, which could be associated with these slightly different motifs, additional unidentified motifs in these diverse and longer promoters or the presence of other genes. The identification of markers associated with the presence/absence of mesifurane in these species awaits future work beyond the scope of this study. Therefore, the absence of predictive bands of 248 and 217 bp using the FaOMT-SI/NO marker in accessions of Fragaria vesca, F. iinumae, F. moschata, and $F$. virginiana (this study; Zorrilla-Fontanesi et al. 2012) suggests that this test is not useful for the prediction of mesifurane in fruits of these species.

Among the $F . \times$ ananassa cultivars, only four ('Aromas,' 'Candonga', 'Elvira,' and 'Pedrone') tested positive for the functional 248 bp FaOMT allele but lacked mesifurane in their fruits. Analysis of the promoter sequence from these accessions confirmed that the sequences were identical to that of line 93-62, indicative of functional $\mathrm{FaOMT}$ alleles in these four inconsistent samples. Sequencing of the open reading frame of $\mathrm{FaOMT}$ in these four accessions would be necessary to rule out the possibility of a non-functional allele despite a functional promoter fragment. A plausible explanation for this nonmatching result is the presence of another inactive gene 
involved in mesifurane biosynthesis in these cultivars. The QTL associated with FaOMT controlled from 42 up to $67.3 \%$ of the phenotypic variance in a 3-year study (Zorrilla-Fontanesi et al. 2012). Therefore, additional yet unidentified loci could also contribute to the natural variation in mesifurane content in strawberry. Indeed, the $\mathrm{FaOMT}$ gene encodes the last enzyme in the biosynthetic pathway, and it is possible that a mutation in another upstream gene limits mesifurane biosynthesis in cultivars with functional $\mathrm{FaOMT}$ alleles such as 'Pedrone.' Pedigree data of these four accessions is limited, and while 'Aromas' (Cal. 87.112-6 × Cal. 88-270-1), 'Candonga' (Planasa 92-38 × 86-032), and 'Pedrone' (not available) may share Californian lines in their pedigree, 'Elvira' ('Gorella' $\times$ 'Vola') represents the European ancestry group. Therefore, there is no clear evidence of sharing common sources of a gene mutation. Another possibility is a non-favorable environment for the production of mesifurane in spite of having a functional FaOMT allele. In this context, an ongoing study using 'Candonga' grown in commercial conditions in Huelva (Spain) has shown accumulation of mesifurane in fruits of this cultivar (unpublished results). Therefore, part of the false positive rate of this marker can be explained by environmental conditions affecting the accumulation of mesifurane in strawberry cultivars. Therefore, the indicators of diagnostic performance of this marker (Table 2) could have been higher if assayed in controlled conditions.

Approximately $42.3 \%$ of the tested strawberry lines were positive for the FaFAD1 gene, consistent with $45 \%$ of the accessions producing levels of $\gamma$-decalactone above threshold in their fruits. This lactone is one of the most environmentally affected volatiles in strawberry (Olbricht et al. 2011; Chambers et al. 2014). Therefore, one possible explanation for a low number of lines producing $\gamma$-decalactone could be that environmental conditions during the collection of fruits from these lines were not favorable for $\gamma$-decalactone production. Environmental effects could explain why 'Galante' and $F$. vesca 596 did not produce $\gamma$-decalactone albeit testing positive for the $140 \mathrm{bp} \mathrm{FaFAD1}$ allele. The four remaining inconsistent results involved samples testing negative for the FaFADl gene but still presenting low but above threshold content of $\gamma$-decalactone, which could be explained by existence of an alternative pathway not yet reported. The accuracy, sensitivity, NPV and ADOR values for this marker were slightly lower than for FaOMT-SI/NO marker. However, the diagnostic performance of both markers here described was comparable to that calculated in controlled conditions for marker Bx215_128, associated with perpetual flowering in octoploid strawberry (Salinas et al. 2017).

\section{Conclusions}

Breakthrough developments in the last few years, such as the availability of strawberry genome sequences (Shulaev et al. 2011; Hirakawa et al. 2014; Jung et al. 2014; Tennessen et al. 2014) and the development of high-throughput genotyping platforms for strawberry (Sánchez-Sevilla et al. 2015; Bassil et al. 2015), will greatly accelerate the identification of causal genes responsible for traits of interest. The main bottleneck for development and validation of candidate genes and markers associated with them will be efficient phenotyping, particularly for metabolic or physiologic traits. Untargeted volatile analysis of fruits is therefore one of such bottlenecks. This panel of 71 strawberry accessions has been already phenotyped for a total of 31 different VOCs and represents a useful tool for the validation of candidate markers predicting the production of different volatiles.

Using this diverse set of accessions, we have shown that the combined FaOMT/FaFAD1 test can predict the production of mesifurane and $\gamma$-decalactone in strawberry with high accuracy 94.03 and $91.55 \%$, respectively. When applied for the selection of cultivars with these VOCs in their fruits, the associated error rate compared to selecting by the phenotype would involve only false positives for mesifurane screening, while for $\gamma$ decalactone, 3 and $6 \%$ would be false positives and false negatives, respectively. However, all false negative samples displayed low content of $\gamma$-decalactone, and thus, qFaFAD1 marker is highly efficient for the prediction of strawberry cultivars with high content of $\gamma$-decalactone. Therefore, implementation of this DNA test in strawberry breeding programs could facilitate efficient parental selection as well as development of new strawberry cultivars with superior flavor. While agarose-based markers are easy to implement in most laboratories, high-throughput marker systems are more efficient for seedling selection during breeding programs, and thus, the development of multiplexed sets of markers for different traits based on Kompetitive Allele Specific PCR (KASP) or high-resolution melting (HRM) would be a step forward in this regard. 
Acknowledgments The authors thank Miguel A. Botella for helpful comments on the manuscript.

Funding information This work was supported by the Spanish Ministry of Economy and Competitivity and FEDER (grant no. AGL2012-40066-C02-01), the GoodBerry Project (European Union's Horizon 2020 research and innovation programme under grant agreement no. 679303), the Spanish Ministry of Economy and Competitivity and FEDER (grant no. RFP2015-00011-00-00), and by a Marie Curie International Outgoing Fellowship within the 7th European Community Framework Programme to I.A (IOF Flavor 328052)

Open Access This article is distributed under the terms of the Creative Commons Attribution 4.0 International License (http:// creativecommons.org/licenses/by/4.0/), which permits unrestricted use, distribution, and reproduction in any medium, provided you give appropriate credit to the original author(s) and the source, provide a link to the Creative Commons license, and indicate if changes were made.

\section{References}

Aliu O, Chung KC (2012) Assessing strength of evidence in diagnostic tests. Plast Reconstr Surg 129:989e-998e

Bassil NV, Davis TM, Zhang H et al (2015) Development and preliminary evaluation of a $90 \mathrm{~K}$ Axiom ${ }^{\circledR}$ SNP array for the allo-octoploid cultivated strawberry Fragaria $\times$ ananassa. BMC Genomics 16:1310

Chambers AH, Pillet J, Plotto A, Bai J, Whitaker VM, Folta KM (2014) Identification of a strawberry flavor gene candidate using an integrated genetic-genomic-analytical chemistry approach. BMC Genomics 15:217

Doyle JJ, Doyle JL (1990) Isolation of plant DNA from fresh tissue. Focus 12:13-15

Faedi W, Mourgues F, Rosati C (2002) Strawberry breeding and varieties: situation and perspectives. Acta Hort 567:51-59

Folta KM, Klee HJ (2016) Sensory sacrifices when we massproduce mass produce. Hortic Res 3:16032

Food and Agriculture Organization of the United Nations. FAOSTAT Database: http://www.fao.org/faostat/en/\#data. Accessed 23 Feb 2017

Gil-Ariza DJ, Amaya I, López-Aranda JM, Botella MA, Valpuesta V, Sánchez-Sevilla JF (2009) Impact of plant breeding on the genetic diversity of cultivated strawberry as revealed by expressed sequence tag-derived simple sequence repeat markers. J Amer Soc Hort Sci 134:337-347

Glas AS, Lijmer JG, Prins MH, Bonsel GJ, Bossuyt PMM (2003) The diagnostic odds ratio: a single indicator of test performance. J Clin Epidemiol 56:1129-1135

Hancock JF (1999) Strawberries. CABI Publishing, Wallingford

Hirakawa H, Shirasawa K, Kosugi S et al (2014) Dissection of the octoploid strawberry genome by deep sequencing of the genomes of Fragaria species. DNA Res 21:169-181

Horvath A, Sanchez-Sevilla JF, Punelli F, Richard L, SesmeroCarrasco R, Leone A, Höefer M, Chartier P, Balsemin E, Barreneche T, Denoyes B (2011) Structured diversity in octoploid strawberry cultivars: importance of the old European germplasm. Ann Appl Biol 159:358-371

Jouquand C, Chandler C, Plotto A, Goodner K (2008) A sensory and chemical analysis of fresh strawberries over harvest dates and seasons reveals factors that affect eating quality. J Amer Soc Hort Sci 133:859-867

Jung S, Ficklin SP, Lee T et al (2014) The Genome Database for Rosaceae (GDR): year 10 update. Nucleic Acids Res 42: D1237-D1244

Klee HJ (2010) Improving the flavor of fresh fruits: genomics, biochemistry, and biotechnology. New Phytol 187:44-56

Larsen M, Poll L (1992) Odour thresholds of some important aroma compounds in strawberries. Z Lebensm Unters Forsch 195:120-123

Larsen M, Poll L, Olsen C (1992) Evaluation of the aroma composition of some strawberry (Fragaria $\times$ ananassa Duch) cultivars by use of odour threshold values. Z Lebensm Unters Forsch 195:536-539

Lerceteau-Köhler E, Moing A, Guerin G, Renaud C, Petit A, Rothan C, Denoyes B (2012) Genetic dissection of fruit quality traits in the octoploid cultivated strawberry highlights the role of homoeo-QTL in their control. Theor Appl Genet 124:1059-1077

López-Aranda JM, Soria C, Santos BM, Miranda L, Domínguez P, Medina-Mínguez JJ (2011) Strawberry production in mild climates of the world: a review of current cultivar use. Int $\mathbf{J}$ Fruit Sci 11:232-244

Negri AS, Allegra D, Simoni L, Rusconi F, Tonelli C, Espen L, Galbiati M (2015) Comparative analysis of fruit aroma patterns in the domesticated wild strawberries "Profumata di Tortona" (F. moschata) and "Regina delle Valli" ( $F$. vesca). Front Plant Sci 6:56

Olbricht K, Ulrich D, Weiss K, Grafe C (2011) Variation in the amounts of selected volatiles in a model population of Fragaria $\times$ ananassa Duch. As influenced by harvest year. J Agric Food Chem 59:944-952

Prat L, Espinoza MI, Agosin E, Silva H (2014) Identification of volatile compounds associated with the aroma of white strawberries (Fragaria chiloensis). J Sci Food Agric 94: 752-759

Rousseau-Gueutin M, Gaston A, Aïnouche A, Aïnouche ML, Olbricht K, Staudt G, Richard L, Denoyes-Rothan B (2009) Tracking the evolutionary history of polyploidy in Fragaria L. (strawberry): new insights from phylogenetic analyses of low-copy nuclear genes. Mol Phylogenet Evol 51:515-530

Rousseau-Gueutin M, Lerceteau-Kohler E, Barrot L, Sargent DJ, Monfort A, Simpson D, Arús P, Guérin G, Denoyes-Rothan B (2008) Comparative genetic mapping between octoploid and diploid Fragaria species reveals a high level of colinearity between their genomes and the essentially disomic behavior of the cultivated octoploid strawberry. Genetics 179: 2045-2060

Salinas NR, Zurn JD, Mathey M, Mookerjee S, Denoyes B, Perrotte J, Potier A, Finn CE, Hancock JF, Stewart P, Bassil NV (2017) Validation of molecular markers associated with perpetual flowering in octoploid Fragaria germplasm. Mol Breeding 37. https://doi.org/10.1007/s11032-017-0672-2

Sánchez-Sevilla JF, Cruz-Rus E, Valpuesta V, Botella MA, Amaya I (2014) Deciphering gamma-decalactone biosynthesis in strawberry fruit using a combination of genetic mapping, RNA-Seq and eQTL analyses. BMC Genomics 15:218 
Sánchez-Sevilla JF, Horvath A, Botella MA, Gaston A, Folta K, Kilian A, Denoyes B, Amaya I (2015) Diversity Arrays Technology (DArT) marker platforms for diversity analysis and linkage mapping in a complex crop, the octoploid cultivated strawberry (Fragaria $\times$ ananassa). PLoS One 10: e0144960

Sargent DJ, Passey T, Šurbanovski N, Lopez Girona E, Kuchta P, Davik J, Harrison R, Passey A, Whitehouse AB, Simpson DW (2012) A microsatellite linkage map for the cultivated strawberry (Fragaria $\times$ ananassa) suggests extensive regions of homozygosity in the genome that may have resulted from breeding and selection. Theor Appl Genet 124:12291240

Schieberle P, Hofmann T (1997) Evaluation of the character impact odorants in fresh strawberry juice by quantitative measurements and sensory studies on model mixtures. J Agric Food Chem 45:227-232

Schwieterman ML, Colquhoun TA, Jaworski EA et al (2014) Strawberry flavor: diverse chemical compositions, a seasonal influence, and effects on sensory perception. PLoS One 9: e88446

Shulaev V, Sargent DJ, Crowhurst RN et al (2011) The genome of woodland strawberry (Fragaria vesca). Nat Genet 43:109-116

Tennessen JA, Govindarajulu R, Ashman T-L, Liston A (2014) Evolutionary origins and dynamics of octoploid strawberry subgenomes revealed by dense targeted capture linkage maps. Genome Biol Evol 6:3295-3313

Ulrich D, Hoberg E, Rapp A, Kecke S (1997) Analysis of strawberry flavour-discrimination of aroma types by quantification of volatile compounds. Z Lebensm Unters Forsch 205: 218-223
Ulrich D, Komes D, Olbricht K, Hoberg E (2007) Diversity of aroma patterns in wild and cultivated Fragaria accessions. Genet Resour Crop Evol 54:1185-1196

Ulrich D, Olbricht K (2013) Diversity of volatile patterns in sixteen Fragaria vesca L. accessions in comparison to cultivars of Fragaria $\times$ ananassa. J Appl Botany Food Qual 86: $37-46$

Ulrich D, Olbricht K (2014) Diversity of metabolite patterns and sensory characters in wild and cultivated strawberries. J Berry Res 4:11-17

Ulrich D, Olbricht K (2016) A search for the ideal flavor of strawberry - comparison of consumer acceptance and metabolite patterns in Fragaria $\times$ ananassa Duch. J Appl Botany Food Qual 89:223-234

Whitaker VM, Osorio LF, Hasing T, Gezan SA (2012) Estimation of genetic parameters for 12 fruit and vegetative traits in the University of Florida strawberry breeding population. J Amer Soc Hort Sci 137:316-324

Zorrilla-Fontanesi Y, Cabeza A, Domínguez P, Medina JJ, Valpuesta V, Denoyes-Rothan B, Sánchez-Sevilla JF, Amaya I (2011) Quantitative trait loci and underlying candidate genes controlling agronomical and fruit quality traits in octoploid strawberry (Fragaria $\times$ ananassa). Theor Appl Genet 123:755-778

Zorrilla-Fontanesi Y, Rambla J-L, Cabeza A, Medina JJ, SánchezSevilla JF, Valpuesta V, Botella MA, Granell A, Amaya I (2012) Genetic analysis of strawberry fruit aroma and identification of O-methyltransferase $\mathrm{FaOMT}$ as the locus controlling natural variation in mesifurane content. Plant Physiol 159:851-870 